\title{
Ion-Selective Electrode for Anionic Surfactants Using Hexadecyl Trimethyl Ammonium Bromide-Sodium Dodecylsulfate as an Active Ionophore
}

\author{
Junwei Wang, Zhiping Du, Wanxu Wang, and Wei Xue \\ Key Laboratory of Surfactant and Interfaces, China Research Institute of Daily Chemical Industry, Shanxi Province, \\ Taiyuan 030001, China \\ Correspondence should be addressed to Wanxu Wang, wanxuwang@163.com
}

Received 9 May 2011; Revised 2 September 2011; Accepted 5 September 2011

Academic Editor: Hassan Ali Zamani

Copyright () 2011 Junwei Wang et al. This is an open access article distributed under the Creative Commons Attribution License, which permits unrestricted use, distribution, and reproduction in any medium, provided the original work is properly cited.

The construction and characteristic performance of PVC membrane electrode responsive to sodium dodecylsulfate (SDS) are described in this paper. The electrode is based on hexadecyl trimethyl ammonium bromide-Sodium dodecylsulfate $\left(\mathrm{CTA}^{+} \mathrm{DS}{ }^{-}\right.$) ion pair as ionophore in PVC membrane, which displays a Nernstian slope of $-58 \pm 0.9 \mathrm{mV} /$ decade in a $5.0 \times 10^{-6}$ to $2.5 \times 10^{-3} \mathrm{~mol}$ $\mathrm{L}^{-1}$ concentration range and a limit of detection of $2.9 \times 10^{-6} \mathrm{~mol} \mathrm{~L}^{-1}$. The electrode can be used for 3 months without showing significant changes in the value of slope or working range. Also the electrode has wide $\mathrm{pH}$ range of application and short response time. The electrode shows a selective response to SDS and a poor response to common inorganic anions. The selective sequence found was $\mathrm{SDS}>\mathrm{HCO}_{3}{ }^{-}>\mathrm{CH}_{3} \mathrm{COO}^{-}>\mathrm{Cl}^{-}>\mathrm{I}^{-}>\mathrm{NO}_{3}{ }^{-} \approx \mathrm{Br}^{-}>\mathrm{F}^{-}>\mathrm{CO}_{3}{ }^{2-}>\mathrm{C}_{6} \mathrm{H}_{5} \mathrm{O}_{7}{ }^{3-}>\mathrm{C}_{2} \mathrm{O}_{4}{ }^{2-}>\mathrm{SO}_{4}{ }^{2-}>$ $\mathrm{C}_{4} \mathrm{H}_{4} \mathrm{O}_{6}{ }^{2-}>\mathrm{SO}_{3}{ }^{2-}>\mathrm{PO}_{4}{ }^{3-}$. The potentiometric selectivity coefficients determined are indicating that common anions would not interfere in the SDS determination. The electrode has been utilized as an end point indicator electrode for potentiometric titration involving hyamine as titrant.

\section{Introduction}

Anionic surfactants are widely used in the industrial and domestic field, for example, in washing agents, household detergents, and personal care products. Traditional analysis methods of anionic surfactant concentration require tedious procedures (such as liquid and gas chromatography), or the use of large amounts of undesired solvents (such as chloroform in the spectrophotometric "Methylene Blue" method) [1-4]. An alternative to these methods is the use of electrodes (such as ion-selective electrodes [5-10] or ion-selective field-effect transistors [11-15]). Potentiometric methods using ion-selective electrodes have found wide applications in diverse fields of analysis for being of low cost, sensitive, and applicable over a wide range of experimental conditions [16].

Surfactant titrations are based on so-called antagonist reaction, where an ionic surfactant reacts with an oppositely charged ion forming a water insoluble salt (ion pair) [17-20]; when the oppositely charged ion surfactants react with each other at equal mol, the potential of the electrode has greatly changed; then the end point can be detected by the electrode.

The use of surfactant selective electrodes for the potentiometric determination of anionic surfactants concentration has been described in several papers. The surfactant selective electrode based on single-walled carbon nanotubes constructed by Najafi et al. [21] was used to determine the concentration of $\mathrm{CTA}^{+}$and $\mathrm{DS}^{-}$. Juan Soto and coworkers $[1,22]$ constructed an ion-selective electrode for anionic surfactants using a new aza-oxa-cycloalkane and cyclam derivative as active ionophore in PVC membrane.

The present work investigates the feasibility of the preparation of stable, long life, high selectivity, and fast response anionic surfactant ion-selective electrode. The PVC membrane electrode is based on hexadecyl trimethyl ammonium bromide-sodium dodecylsulfate $\left(\mathrm{CTA}^{+} \mathrm{DS}^{-}\right)$ion pair as ionophore and di-n-octyl-phthalate (DOP) as plasticizer. The sensitivity and stability offered by this electrode configuration are high enough to allow accurate determination of 
low levels of anionic surfactant by direct potentiometry and potentiometric titration.

\section{Experimental}

2.1. Reagents. Sodium dodecylsulfate (SDS), hexadecyl trimethyl ammonium bromide $(\mathrm{CTAB})$, hyamine and poly (vinyl chloride) of high molecular weight were from Aldrich (analytical grade). Di-n-octyl-phthalate (DOP) and tetrahydrofuran (THF) are both from Tianjin kermel Chemical Reagent Company. All other reagents used for the preparation of electrode were of analytical grade. Distilled water was used for the preparation of the solutions and for the cleaning of all glassware and apparatus in the experiments.

2.2. Apparatus. The potentiometric measurements were performed with a $\mathrm{pH}^{\mathrm{s}} 3 \mathrm{C} \mathrm{pH} / \mathrm{mV}$ meter and a saturated calomel electrode (SCE) was used as external reference electrode. $\mathrm{pH}^{\mathrm{s}}$ $3 \mathrm{C} \mathrm{pH} / \mathrm{mV}$ meter and saturated calomel electrode were purchased from Shanghai Precision and Scientific Instrument Co., Ltd. The indicating electrode was self-made anionic surfactant selective electrode. Potentiometric titrations were conducted with the help of an automatic burette and a titroprocessor (Beijing Xianquweifeng Technology Development Company) using a $25.0 \pm 0.1^{\circ} \mathrm{C}$ water-thermostated vessel and an automatic burette.

2.3. Preparation of Electrode. The surfactant ion-selective electrode was made according to the classical method described in the literature [23] and the preparation could be formulated as follows.

2.3.1. Preparation of the Ion Pair. The ion pair $\mathrm{CTA}^{+} \mathrm{DS}^{-}$was prepared by pouring together equimolar amounts of sodium dodecyl sulfate (SDS) and hexadecyl trimethyl ammonium bromide (CTAB) in hot aqueous solution. The ion pair $\mathrm{CTA}^{+} \mathrm{DS}^{-}$is formed as a white precipitate, which was filtered off, washed with distilled water, and recrystallized twice from hot acetone.

2.3.2. Preparation of the Membrane. The best membranes, obtained with PVC:DOP 2:3, contained $10^{-3} \mathrm{~mol}$ $\mathrm{CTA}^{+} \mathrm{DS}^{-}$ion pair per kilogram of PVC and DOP mixture. $\mathrm{PVC}, \mathrm{DOP}$, and $\mathrm{CTA}^{+} \mathrm{DS}^{-}$ion pair were dissolved in tetrahydrofuran, poured on a flat-bottomed glass dish. Tetrahydrofuran evaporated from the solution at room temperature for $48 \mathrm{~h}$, and then the requisite membrane was obtained.

2.3.3. Construction of the Electrode. A disk of $1.0 \mathrm{~cm}$ in diameter was cut from the obtained membrane and attached to the end of a PVC tube using the solution of PVC dissolved in tetrahydrofuran (THF) as adhesive. The $\mathrm{Ag} / \mathrm{AgCl}$ electrode was used as inner reference electrode. $1.0 \times 10^{-3} \mathrm{~mol} \mathrm{~L}^{-1}$ SDS and $1.0 \times 10^{-3} \mathrm{~mol} \mathrm{~L}^{-1} \mathrm{KCl}$ mixture solution was used as inner solution. Respectively, to fabricate an electrode, the electrode was preconditioned in $10^{-3} \mathrm{~mol} \mathrm{~L}^{-1}$ SDS solution for $24 \mathrm{~h}$.
2.4. Theory. A rapid and reliable potentiometric analysis method with surfactant ion-selective electrode has been developed for the determination of surfactants; surfactant concentration and potential comply with Nernstian equation written as

$$
E=E^{\circ}+2.303 \frac{R T}{z F} \log a_{\mathrm{DS}^{-}},
$$

where $E$ stands for the equilibrium electrode potential, $E^{\circ}$ is the standard electrode formal potential, $R$ is the gas constant, $T$ is the temperature, $z$ is the transfer electron number of electrode reaction, $F$ is the Faradays constant, and $a_{\mathrm{DS}}$ is the activity of the SDS solution. Therefore, the surfactant concentration can be acquired from the potentiometry measured using surfactant ion-selective electrode.

2.5. Emf Measurements and Titration Procedure. The external reference electrode was a saturated calomel electrode and self-made electrode was used for all EMF measurements. Potentiometric measurements were carried out by using the following cell assembly: external reference electrode, Saturated KCl solution, sample solution, PVC membrane, inner solution, and $\mathrm{Ag} / \mathrm{AgCl}$. All potential measurements were carried out on a $\mathrm{pH}^{\mathrm{s}} 3 \mathrm{C} \mathrm{pH} / \mathrm{mV}$ meter. Potentiometric selectivity coefficients were determined according to the fixed interference method using $2.5 \times 10^{-2} \mathrm{~mol} \mathrm{~L}^{-1}$ solution of interfering ion. Calibration curves were constructed by plotting the potential, $E$, versus the logarithm of the sodium dodecyl sulfate (SDS) concentration.

The electrode has been calibrated with standard solutions of SDS in the range of $1.0 \times 10^{-7}$ to $5.0 \times 10^{-2} \mathrm{~mol} \mathrm{~L}^{-1}$. The volume of tested solution used for titration was $25.0 \mathrm{~mL}$. The titrant dosage rate was $0.1 \mathrm{~mL} \mathrm{~s}^{-1}$. The concentration of titrant hyamine was $4.043 \times 10^{-3} \mathrm{~mol} \mathrm{~L}^{-1}$. All the measurements and titration were performed at $25.0 \pm 0.1^{\circ} \mathrm{C}$.

\section{Results and Discussion}

3.1. Influence of Membrane Composition. The ion pair $\mathrm{CTA}^{+} \mathrm{DS}^{-}$was synthesized and tested as ionophore in PVC membrane. As it has been reported, the response of ionselective electrodes in terms of selectivity and sensitivity depends not only on the ionophore but also on the final composition of the membrane ingredients. Therefore, in a first step several compositions of the membrane ingredients ionophore, plasticizer, and PVC were tested. All the membranes prepared were studied against SDS. The three electrodes (1-3) prepared with different membrane compositions were shown in Table 1. The membrane of electrodes 1, 2, and 3 had a similar composition, and the only difference was the content of ion pair. A comparison of the response characteristics of electrodes 1-3 against SDS is shown in Figure 1 and Table 1. It can be found that Electrode 2 with the composition (wt\%) of DOP (60\%), PVC (33\%), and ion pair (2\%) showed a better performance than electrodes 1 and 3. On one hand it had the lowest detection limit and the best linear correlation coefficient, on the other hand the slope value is the nearest to theory 
TABLE 1: Response characteristics of the anionic surfactant-selective electrode based on PVC membrane to SDS with different composition.

\begin{tabular}{|c|c|c|c|c|}
\hline Membrane $^{\mathrm{a}}$ & Slope (mV/decade) & Linear range $\left(\mathrm{mol} \mathrm{L}^{-1}\right)$ & Detection limit $\left(\mathrm{mol} \mathrm{L}^{-1}\right)$ & Correlation coefficient $(r)$ \\
\hline 1 & $-50.7 \pm 1.2$ & $7.5 \times 10^{-6}$ to $2.5 \times 10^{-3}$ & $4.6 \times 10^{-6}$ & $0.9972 \pm 0.0004$ \\
\hline 2 & $-58.0 \pm 0.9$ & $5.0 \times 10^{-6}$ to $2.5 \times 10^{-3}$ & $2.9 \times 10^{-6}$ & $0.9987 \pm 0.0003$ \\
\hline 3 & $-65.5 \pm 2.4$ & $7.5 \times 10^{-6}$ to $2.5 \times 10^{-3}$ & $5.9 \times 10^{-6}$ & $0.9935 \pm 0.0007$ \\
\hline
\end{tabular}

angredients of membrane (wt \%): (1) DOP (60\%), PVC (34\%), ion pair (1\%), (2) DOP (60\%), PVC (33\%), ion pair (2\%), (3) DOP (60\%), PVC (32\%), ion pair $(3 \%)$.

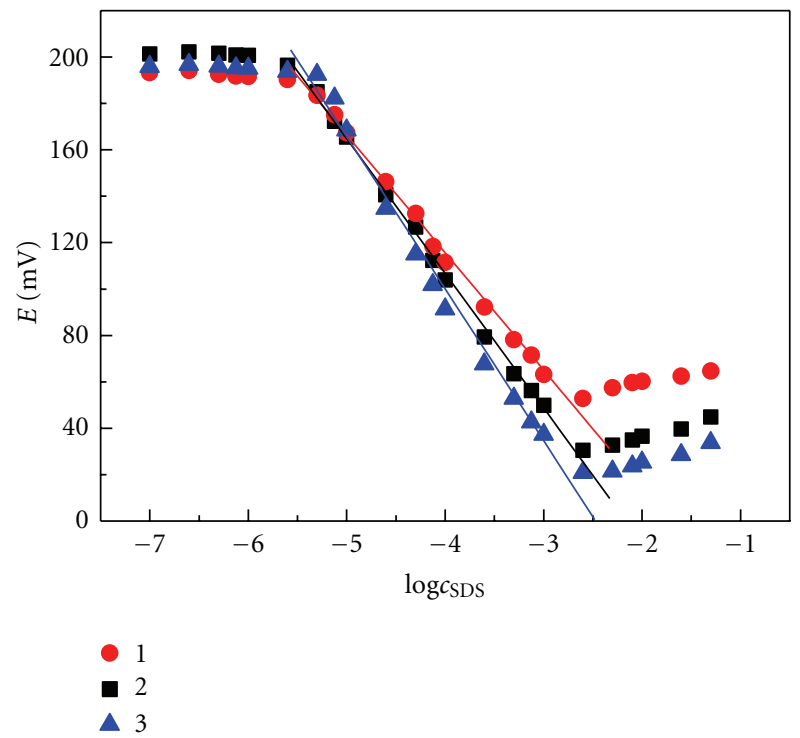

Figure 1: Potential response of the surfactant-selective electrode with different composition to SDS. Ingredients (wt\%): •: DOP (60\%), PVC (34\%), ion pair (1\%), ш: DOP (60\%), PVC (33\%), ion pair (2\%), $\mathbf{\Delta}$ : DOP (60\%), PVC (32\%), ion pair (3\%).

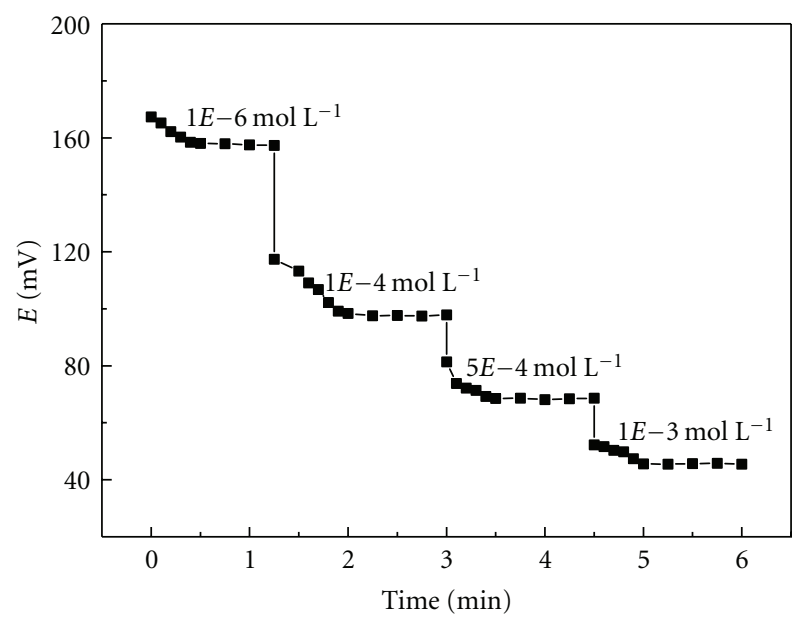

FIGURE 2: Response time of anionic surfactant selective electrode for step changes in different concentration of SDS solution.

value $59.2 \mathrm{mV} /$ decade. So we chose the composition as the ingredients of electrode membrane for the following studies.

3.2. Response Behavior of the Electrode. Electromotive force of the membrane electrode 2 assembly dipped in the

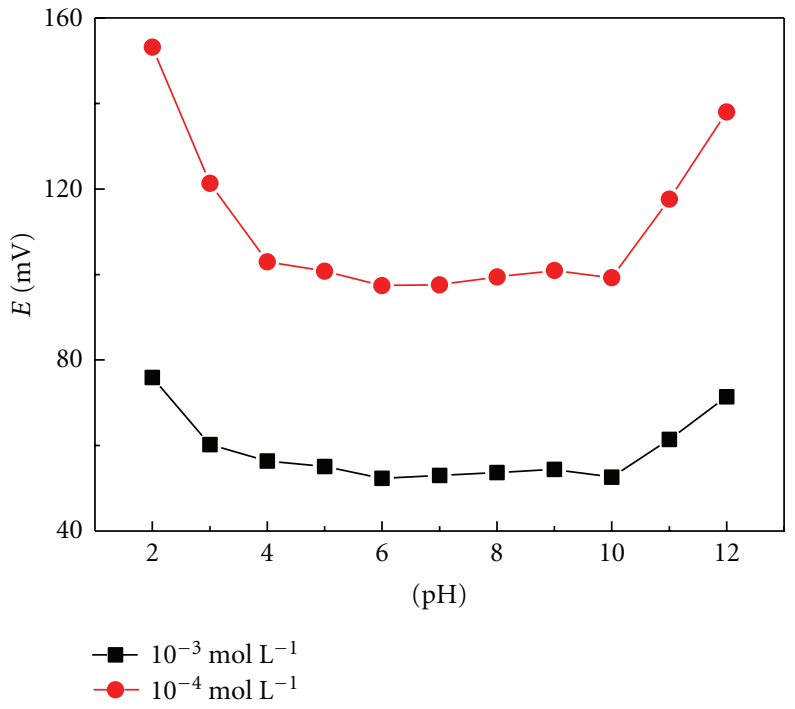

FIGURE 3: Effect of $\mathrm{pH}$ on the potentials of anionic surfactant selective electrode in $1 \times 10^{-4}$ and $1 \times 10^{-3} \mathrm{~mol} \mathrm{~L}^{-1}$ SDS solution.

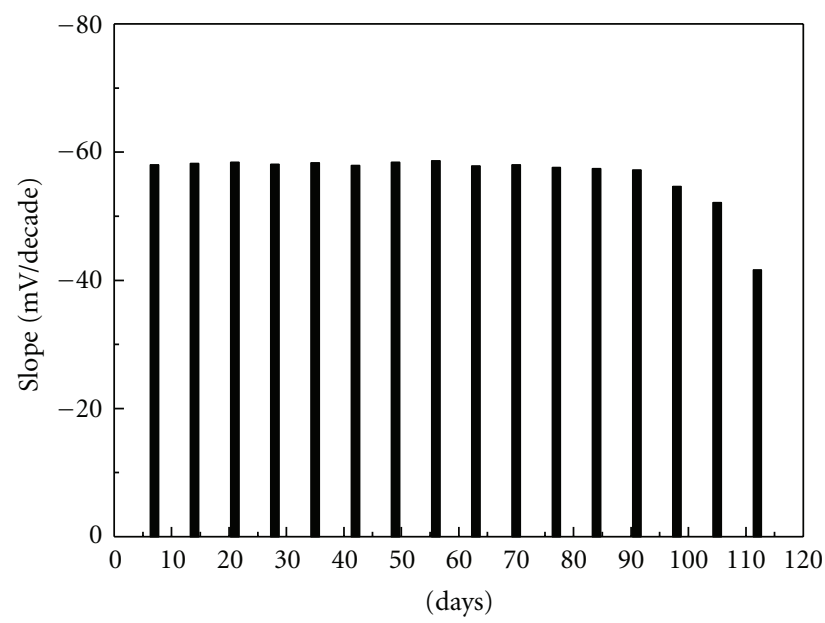

FIGURE 4: Plot of the slope of anionic surfactant selective electrode in the presence of SDS versus time (days).

solution of anionic surfactant SDS investigated was given by Nernstian equation. The response characteristics of anion surfactant selective electrode in solutions of sodium dodecylsulfate (SDS) were shown in Figure 1 (curve 2). Statistical evaluation of the electrode characteristics was given in Table 1 (membrane 2). The slope value and correlation coefficients were calculated from the linear region 


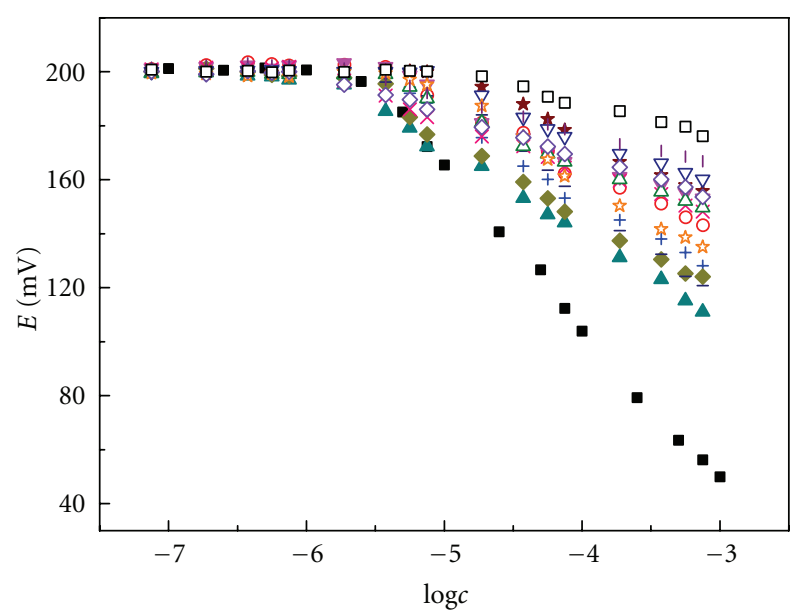

FIgURE 5: Response of anionic surfactant selective electrode in the presence of certain anions: $(\boldsymbol{\square}) \mathrm{SDS} ;(\bigcirc) \mathrm{F}^{-} ;(+) \mathrm{Cl}^{-} ;(\boldsymbol{\Delta}) \mathrm{Br}^{-} ;(\boldsymbol{\nabla})$

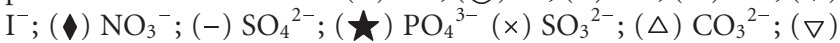

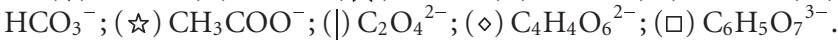

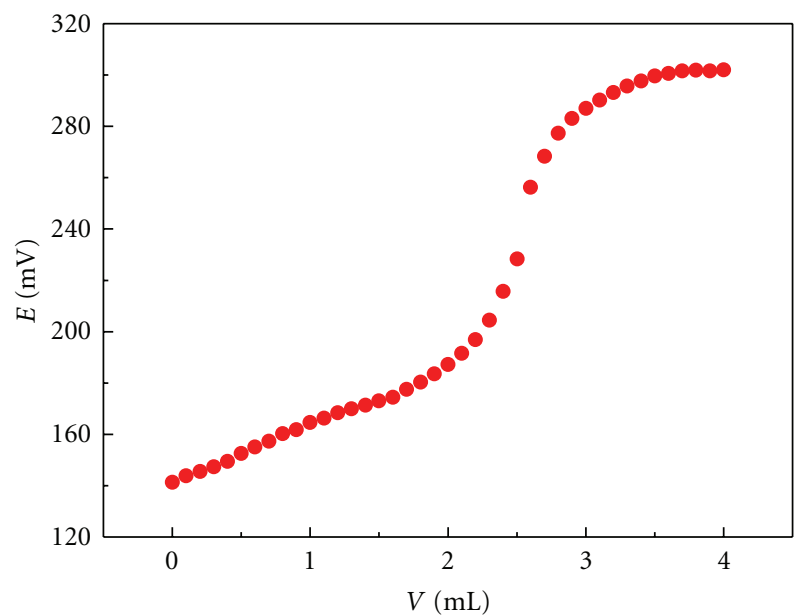

FIgURE 6: Potentiometric titration curve of $25.0 \mathrm{~mL}$ tested SDS solution with $4.043 \times 10^{-3} \mathrm{~mol} \mathrm{~L}^{-1}$ hyamine as titrant in water, using the electrode as an indicator electrode.

of the calibration graph of the measurements using linear regression analysis.

Detection limit is defined as the concentration of SDS corresponding to the intersection of the extrapolated linear segments of the calibration graph [24] which was $2.9 \times$ $10^{-6} \mathrm{~mol} \mathrm{~L}^{-1}$. The electrode investigated showed Nernstian response $(-58.0 \pm 0.9 \mathrm{mV} /$ decade $)$ between $5.0 \times 10^{-6}$ and $2.5 \times 10^{-3} \mathrm{~mol} \mathrm{~L}^{-1}$ for SDS. It can be seen that the electrode exhibits linear response for SDS.

3.3. Response Time. The static response time of the electrode was measured after successive immersion of the electrode in a series of SDS solutions, from $1.0 \times 10^{-5}$ to $1.0 \times 10^{-3} \mathrm{~mol} \mathrm{~L}^{-1}$. The response time of electrode was evaluated by measuring the time required to achieve a steady-state potential $[25,26]$. As shown in Figure 2, a response time of $40 \mathrm{~s}$ was found as the time required for the electrode to reach a potential within $\pm 1 \mathrm{mV}$ of the final equilibrium. The standard deviation of the
TABLE 2: The life time study of the anionic surfactant selective electrode.

\begin{tabular}{lccc}
\hline $\begin{array}{l}\text { Period } \\
(\text { weeks })\end{array}$ & $\begin{array}{c}\text { Slope } \\
(\mathrm{mV} / \text { decade })\end{array}$ & $\begin{array}{c}\text { Linear range } \\
\left(\mathrm{mol} \mathrm{L}^{-1}\right)\end{array}$ & $\begin{array}{c}\text { Detection limit } \\
\left(\mathrm{mol} \mathrm{L}^{-1}\right)\end{array}$ \\
\hline 1 & -58.0 & $5.0 \times 10^{-6}$ to $2.5 \times 10^{-3}$ & $2.9 \times 10^{-6}$ \\
2 & -58.2 & $4.6 \times 10^{-6}$ to $2.5 \times 10^{-3}$ & $2.9 \times 10^{-6}$ \\
3 & -58.4 & $4.7 \times 10^{-6}$ to $2.5 \times 10^{-3}$ & $3.0 \times 10^{-6}$ \\
4 & -58.1 & $5.2 \times 10^{-6}$ to $2.5 \times 10^{-3}$ & $3.0 \times 10^{-6}$ \\
5 & -58.3 & $5.5 \times 10^{-6}$ to $2.7 \times 10^{-3}$ & $3.4 \times 10^{-6}$ \\
6 & -57.9 & $5.9 \times 10^{-6}$ to $1.9 \times 10^{-3}$ & $2.2 \times 10^{-6}$ \\
7 & -58.4 & $6.4 \times 10^{-6}$ to $2.2 \times 10^{-3}$ & $3.9 \times 10^{-6}$ \\
8 & -58.6 & $5.4 \times 10^{-6}$ to $1.8 \times 10^{-3}$ & $2.6 \times 10^{-6}$ \\
9 & -57.8 & $7.1 \times 10^{-6}$ to $1.5 \times 10^{-3}$ & $4.9 \times 10^{-6}$ \\
10 & -58.0 & $6.7 \times 10^{-6}$ to $2.8 \times 10^{-3}$ & $3.5 \times 10^{-6}$ \\
11 & -57.6 & $8.1 \times 10^{-6}$ to $2.4 \times 10^{-3}$ & $4.3 \times 10^{-6}$ \\
12 & -57.4 & $7.8 \times 10^{-6}$ to $3.1 \times 10^{-3}$ & $4.1 \times 10^{-6}$ \\
13 & -57.2 & $8.2 \times 10^{-6}$ to $3.4 \times 10^{-3}$ & $5.0 \times 10^{-6}$ \\
14 & -54.6 & $9.1 \times 10^{-6}$ to $3.5 \times 10^{-3}$ & $6.1 \times 10^{-6}$ \\
15 & -52.1 & $1.1 \times 10^{-5}$ to $2.9 \times 10^{-3}$ & $7.6 \times 10^{-6}$ \\
16 & -41.6 & $2.4 \times 10^{-5}$ to $3.1 \times 10^{-3}$ & $1.6 \times 10^{-5}$ \\
\hline
\end{tabular}

response time calculated from four measurements was $\pm 5 \mathrm{~s}$; the response time of the electrode was $40 \pm 5 \mathrm{~s}$.

3.4. Effect of $\mathrm{pH}$. The influence of $\mathrm{pH}$ on the potential response of the electrode was studied at a fixed concentration of SDS of $1 \times 10^{-4} \mathrm{~mol} \mathrm{~L}^{-1}$ and $1 \times 10^{-3} \mathrm{~mol} \mathrm{~L}^{-1}$ over the $\mathrm{pH}$ range of $2-12$. $\mathrm{CTA}^{+} \mathrm{DS}^{-}$ion pair mainly response to DS $^{-}$. $\mathrm{DS}^{-}$can combine with $\mathrm{H}^{+}$at low $\mathrm{pH}$, and then $\mathrm{DSH}$ formed. At low $\mathrm{pH}\left[\mathrm{H}^{+}\right]>\left[\mathrm{DS}^{-}\right]$, the concentration of $\mathrm{DS}^{-}$ was decreased in the solution which is probably related to the increasing of DSH concentration. The $\mathrm{pH}$ values higher than 10 also affected the potential response of electrode. Potential increases most likely due to a membrane response to the $\mathrm{OH}^{-}$anion, that is because in such medium $\mathrm{OH}^{-}$ions compete with $\mathrm{DS}^{-}$ions. So out of the $\mathrm{pH}$ range 4 and 10 , the potential was not the same as in the $\mathrm{pH}$ range 4-10. As illustrated in Figure 3, potentials remained constant between $\mathrm{pH} 4-10$, which was chosen as the $\mathrm{pH}$ range for the studies [1].

3.5. Life Time of the Electrode. The electrode characteristics obtained at various time intervals were illustrated in Table 2 and Figure 4. The electrode exhibited good reproducibility in slope, linear concentration range, and detection limit for 13 weeks, but slight drifts in its slope and detection limit were observed after 14 weeks. The life time of the electrode was more than 3 months [1].

3.6. Determination of Potentiometric Selectivity Coefficients. We carried several studies with the electrode in relation to its response in the presence of SDS. As can be seen in Figure 5, the electrode displayed a remarkable selective response to SDS and a very poor change of the potential in the presence of the anions $\mathrm{F}^{-}, \mathrm{Cl}^{-}, \mathrm{Br}^{-}, \mathrm{I}^{-}, \mathrm{NO}_{3}{ }^{-}, \mathrm{SO}_{4}{ }^{2-}, \mathrm{PO}_{4}{ }^{3-}$, 
TABLE 3: Potentiometric selective coefficients for anionic surfactant selective electrode.

\begin{tabular}{lccc}
\hline Interfering ion & $k_{\mathrm{DS}^{-}, X^{-}}^{\mathrm{pot}}(\log )$ & Interfering ion & $k_{\mathrm{DS}}^{\mathrm{pot}, X^{-}}(\log )$ \\
\hline $\mathrm{F}^{-}$ & -4.34 & $\mathrm{SO}_{3}{ }^{2-}$ & -5.02 \\
$\mathrm{Cl}^{-}$ & -3.94 & $\mathrm{CO}_{3}{ }^{2-}$ & -4.55 \\
$\mathrm{Br}^{-}$ & -4.27 & $\mathrm{HCO}_{3}{ }^{-}$ & -3.46 \\
$\mathrm{I}^{-}$ & -4.22 & $\mathrm{CH}_{3} \mathrm{COO}^{-}$ & -3.55 \\
$\mathrm{NO}_{3}{ }^{-}$ & -4.26 & $\mathrm{C}_{2} \mathrm{O}_{4}{ }^{2-}$ & -4.85 \\
$\mathrm{SO}_{4}{ }^{2-}$ & -4.89 & $\left(\mathrm{C}_{4} \mathrm{H}_{4} \mathrm{O}_{6}{ }^{2-}\right)^{\mathrm{a}}$ & -4.97 \\
$\mathrm{PO}_{4}{ }^{3-}$ & -5.13 & $\left(\mathrm{C}_{6} \mathrm{H}_{5} \mathrm{O}_{7}{ }^{3-}\right)^{\mathrm{b}}$ & -4.59 \\
\hline
\end{tabular}

tartrate, ${ }^{\mathrm{b}}$ citrate.

TABLE 4: Results of determining the concentration of SDS by potentiometric titration using anionic surfactant selective electrode compared with the two-phase titration in sample solutions.

\begin{tabular}{|c|c|c|c|c|c|}
\hline \multirow{2}{*}{ Number } & \multirow{2}{*}{$V_{\mathrm{SDS}}(\mathrm{mL})$} & \multicolumn{2}{|c|}{ Potentiometric titration } & \multicolumn{2}{|c|}{ Two-phase titration } \\
\hline & & $\mathrm{V}_{\text {Hyamine }}(\mathrm{mL})$ & $\mathrm{CSDS}_{\mathrm{SDO}}\left(\mathrm{mol} \mathrm{L}^{-1}\right)$ & $\mathrm{V}_{\text {Hyamine }}(\mathrm{mL})$ & $\mathrm{c}_{\mathrm{SDS}}\left(\mathrm{mol} \mathrm{L}^{-1}\right)$ \\
\hline 1 & 25.0 & 2.53 & $4.09 \times 10^{-4}$ & 2.51 & $4.06 \times 10^{-4}$ \\
\hline 2 & 25.0 & 2.54 & $4.11 \times 10^{-4}$ & 2.52 & $4.08 \times 10^{-4}$ \\
\hline 3 & 25.0 & 2.54 & $4.11 \times 10^{-4}$ & 2.53 & $4.09 \times 10^{-4}$ \\
\hline Average & 25.0 & 2.54 & $4.11 \times 10^{-4}$ & 2.52 & $4.08 \times 10^{-4}$ \\
\hline $\operatorname{RSD}(\%)^{\mathrm{a}}$ & & & 1.41 & & 1.58 \\
\hline
\end{tabular}

aelative standard deviation of potentiometric titration and two-phase titration method for triplicate measurements.

TABLE 5: Comparison of the results obtained by the potentiometric and two-phase titration of commercial detergents.

\begin{tabular}{lcc}
\hline Sample & \multicolumn{2}{c}{ SDS (wt\%) } \\
& Potentiometric titration & Two-phase titration \\
\hline $1^{\mathrm{a}}$ & 14.37 & 14.23 \\
$2^{\mathrm{a}}$ & 14.34 & 14.20 \\
$3^{\mathrm{a}}$ & 14.39 & 14.26 \\
\hline RSD $(\%)^{\mathrm{b}}$ & 2.05 & 2.45 \\
\hline
\end{tabular}

a Number 1, 2, 3: washing liquid (SDS, glycerine, sodium chloride, diethanolamid, and additives).

${ }^{\mathrm{b}}$ Relative standard deviation of potentiometric method for triplicate measurements.

$\mathrm{SO}_{3}{ }^{2-}, \mathrm{CO}_{3}{ }^{2-}, \mathrm{HCO}_{3}{ }^{-}, \mathrm{CH}_{3} \mathrm{COO}^{-}, \mathrm{C}_{2} \mathrm{O}_{4}{ }^{2-}, \mathrm{C}_{4} \mathrm{H}_{4} \mathrm{O}_{6}{ }^{2-}$, and $\mathrm{C}_{6} \mathrm{H}_{5} \mathrm{O}_{7}{ }^{3-}$. As it can be seen that the electrode displays negligible response to these anions when compared with that found for SDS.

In order to quantify the selective behavior found for the electrode towards SDS, we have carried out studies to determine potentiometric selectivity coefficients. Selectivity is one of the most important characteristics of electrodes that gives an idea of the preference of the electrode for the primary ion with respect to potentially interfering species and display the ability to distinguish this ion from a complex mixture. The potentiometric selectivity coefficients $\left(k_{\mathrm{DS}}^{\mathrm{pot}, X^{-}}\right)$of the electrode were calculated by means of the fixed interference method considering SDS as the principal anion and using concentration of $2.5 \times 10^{-2} \mathrm{~mol} \mathrm{~L}^{-1}$ for interfering anions. $k_{\mathrm{DS}^{-}, X^{-}}^{\text {pot }}$ was calculated with the following equation [27]

$$
K_{i j}^{\mathrm{pot}}=\frac{a_{\mathrm{DS}^{-}}}{\left(a_{X^{-}}\right)^{z_{\mathrm{DS}}-1 z_{X^{-}}}}
$$

where $a_{\mathrm{DS}}$ is the activity of the primary ion of $\mathrm{DS}^{-}, a_{X^{-}}$is the activity of the corresponding interfering ion, and $z_{\mathrm{DS}^{-}}$and $z_{X^{-}}$are the corresponding charge of the primary ion and the interfering ion, respectively. The calculated potentiometric selectivity coefficients were listed in Table 3 . The selectivity sequence for the electrode was SDS $>\mathrm{HCO}_{3}{ }^{-}>\mathrm{CH}_{3} \mathrm{COO}^{-}>$ $\mathrm{Cl}^{-}>\mathrm{I}^{-}>\mathrm{NO}_{3}{ }^{-} \approx \mathrm{Br}^{-}>\mathrm{F}^{-}>\mathrm{CO}_{3}{ }^{2-}>\mathrm{C}_{6} \mathrm{H}_{5} \mathrm{O}_{7}{ }^{3-}>$ $\mathrm{C}_{2} \mathrm{O}_{4}{ }^{2-}>\mathrm{SO}_{4}{ }^{2-}>\mathrm{C}_{4} \mathrm{H}_{4} \mathrm{O}_{6}{ }^{2-}>\mathrm{SO}_{3}{ }^{2-}>\mathrm{PO}_{4}{ }^{3-}$. As can be seen in Table 3, the logarithm of the potentiometric selectivity coefficients determined for the electrode are generally lower than -3.0 indicating that most of the anions would not significantly disturb the determination of SDS in real samples.

3.7. Analytical Applications. Our investigations showed that the electrode can not only be used for direct determination of SDS, but also was found useful as a sensor in titration of SDS with precipitating reagent (hyamine). As an example, it was applied in the titration of an SDS solution with hyamine. The amount of SDS in solution can be accurately determined by the electrode. In order to determine the concentration of SDS in model solutions, the electrode has been used for the determination of SDS in water by potentiometric titration in conjunction with SCE (saturated calomel electrode) as reference electrode and the results have been compared with those obtained using the reference standard technique the two-phase titration [28]. A typical sigmoid shape titration curve obtained from the titration of SDS was shown in Figure 6. The titration volume was estimated at the inflection point of the titration curve. As shown in Table 4, the results recorded by potentiometric titration are in good accordance with those given by the two-phase titration. Relative standard 
TABLE 6: Comparison table with previously similar reported works.

\begin{tabular}{lcccc}
\hline Ionophore & Slope $(\mathrm{mV} /$ decade $)$ & Linear range $\left(\mathrm{mol} \mathrm{L}^{-1}\right)$ & Detection limit $\left(\mathrm{mol} \mathrm{L}^{-1}\right)$ & $\mathrm{pH} \mathrm{range}^{-6}$ \\
\hline New cyclic aza-oxa-cycloalkane $^{\mathrm{a}}$ & $-57.7 \pm 0.2$ & $3.3 \times 10^{-6}$ to $6.7 \times 10^{-3}$ & $2.9 \times 10^{-6}$ & $4.5-8$ \\
Cyclam derivative $^{\mathrm{b}}$ & $-60.0 \pm 0.9$ & $7.9 \times 10^{-6}$ to $2.0 \times 10^{-3}$ & $4.0 \times 10^{-6}$ & $5-8.5$ \\
Single walled carbon nanotubes $^{\mathrm{c}}$ & -59.5 & $9.0 \times 10^{-5}$ to $5.0 \times 10^{-3}$ & $5.2 \times 10^{-6}$ & Without mention \\
CTA $^{+}$DS $^{-}$ion pair $^{\mathrm{d}}$ & $-58.0 \pm 0.9$ & $5.0 \times 10^{-6}$ to $2.5 \times 10^{-3}$ & $2.9 \times 10^{-6}$ & $4-10$ \\
\hline
\end{tabular}

${ }^{\mathrm{a}}$ Reference [22], ${ }^{\mathrm{b}}$ Reference [1], ${ }^{\mathrm{c}}$ Reference [21], ${ }^{\mathrm{d}}$ Textual content.

deviation of potentiometric titration and two-phase titration method for triplicate measurements are less than 1.6\%.

For the determination of SDS in commercial detergents, 15-30 mg sample was dissolved in $2 \mathrm{~mL}$ methanol and diluted to $100 \mathrm{~mL}$ with water and $20 \mathrm{~mL}$ portion applied to the determination of SDS in samples by the electrode. The results of the potentiometric titration using the electrode were compared with those obtained using the two-phase titration. As shown in Table 5, the results recorded by the potentiometric titration are in good accordance with those given by two-phase titration.

\section{Conclusion}

Comparison with previously similar reported works was shown in Table 6. It can be found that the response slope to SDS of those electrodes was similar. The membrane containing new cyclic aza-oxa-cycloalkane as ionophore had the widest linear range and the lowest detection limit. The membrane containing $\mathrm{CTA}^{+} \mathrm{DS}^{-}$ion pair as ionophore had the widest $\mathrm{pH}$ usage range and also had the lowest detection limit. An anionic surfactant selective electrode based on $\mathrm{CTA}^{+} \mathrm{DS}^{-}$ion pair as an active ionophore provided advantages of easy preparation, simplicity, fast, and clean method of analysis of anion surfactant. This electrode displayed a Nernstian slope of $-58.0 \pm 0.9 \mathrm{mV} /$ decade over the $5.0 \times 10^{-6}$ to $2.5 \times 10^{-3} \mathrm{~mol} \mathrm{~L}^{-1}$ concentration range and shows a limit of detection of $2.9 \times 10^{-6} \mathrm{~mol} \mathrm{~L}^{-1}$. The electrode can be applied in a $\mathrm{pH}$ range of 4-10. Response time is $40 \pm 5 \mathrm{~s}$ in average and can be used more than 3 months without showing significant changes in the value of slope. The electrode showed a clear anionic response to SDS. The selective sequence found for the electrode was SDS $>$ $\mathrm{HCO}_{3}^{-}>\mathrm{CH}_{3} \mathrm{COO}^{-}>\mathrm{Cl}^{-}>\mathrm{I}^{-}>\mathrm{NO}_{3}^{-} \approx \mathrm{Br}^{-}>\mathrm{F}^{-}>$ $\mathrm{CO}_{3}{ }^{2-}>\mathrm{C}_{6} \mathrm{H}_{5} \mathrm{O}_{7}{ }^{3-}>\mathrm{C}_{2} \mathrm{O}_{4}{ }^{2-}>\mathrm{SO}_{4}{ }^{2-}>\mathrm{C}_{4} \mathrm{H}_{4} \mathrm{O}_{6}{ }^{2-}>$ $\mathrm{SO}_{3}{ }^{2-}>\mathrm{PO}_{4}{ }^{3-}$. Furthermore, the potentiometric selectivity coefficients determined were relatively low, indicating that common anions would not interfere in the SDS determination. Also it can be used for the determination of SDS in water samples by titration procedures.

\section{Acknowledgments}

This work was supported by Natural Fund of Shanxi Province (2010011017), Natural Science Fund of China (21073234, 21103228), and Shanxi Province Science Fund for Youths (2011021010-2).

\section{References}

[1] J. L. Lizondo-Sabater, R. M. Máñez, F. Sancenón, M. J. Seguí, and J. Soto, "Ion-selective electrodes for anionic surfactants using a cyclam derivative as ionophore," Talanta, vol. 75, no. 1, pp. 317-325, 2008.

[2] A. Shaheen, I. Kaur, and R. K. Mahajan, "Potentiometric studies of micellization behavior of cationic surfactants in the presence of glycol additives and triblock polymer (Pluronic F68), using surfactant-selective sensors based on neutral ionpair complexes," Industrial \& Engineering Chemistry Research, vol. 46, no. 13, pp. 4706-4709, 2007.

[3] K. Vytras, J. Kalous, and J. Jezkova, "Automated potentiometry as an ecologic alternative to two-phase titrations of surfactants," Egypt Journal of Analytical Chemistry, vol. 6, no. 1, pp. 107-123, 1997.

[4] C. Vogt and K. Heinig, "Trace analysis of surfactants using chromatographic and electrophoretic techniques," Fresenius' Journal of Analytical Chemistry, vol. 363, no. 7, pp. 612-618, 1999.

[5] Q. He and H. Chen, "Flow injection spectrophotometric determination of anionic surfactants using methyl orange as chromogenic reagent," Fresenius' Journal of Analytical Chemistry, vol. 367, no. 3, pp. 270-274, 2000.

[6] T. Fujinaga, S. Okazaki, and H. Freiser, "Ion selective electrodes responsive to anionic detergents," Analytical Chemistry, vol. 46, no. 12, pp. 1842-1844, 1974.

[7] M. Gerlache, Z. Sentürk, J. C. Viré, and J. M. Kauffmann, "Potentiometric analysis of ionic surfactants by a new type of ion-selective electrode," Analytica Chimica Acta, vol. 349, no. 1-3, pp. 59-65, 1997.

[8] B. Kovács, B. Csóka, G. Nagy, and A. Ivaska, "All-solidstate surfactant sensing electrode using conductive polymer as internal electric contact," Analytica Chimica Acta, vol. 437, no. 1, pp. 67-76, 2001.

[9] N. Alizadeh and H. K. Tazekendi, "Linear alkylbenzenesulfonate (LAS) ion-selective electrode based on electrochemically prepared polypyrrole and PVC," Sensors and Actuators B, vol. 75, no. 1-2, pp. 5-10, 2001.

[10] J. Sànchez and M. Del Valle, "A new potentiometric photocurable membrane selective to anionic surfactants," Electroanalysis, vol. 13, no. 6, pp. 471-476, 2001.

[11] R. K. Mahajan and A. Shaheen, "Effect of various additives on the performance of a newly developed PVC based potentiometric sensor for anionic surfactants," Journal of Colloid and Interface Science, vol. 326, no. 1, pp. 191-195, 2008.

[12] L. Campanella, M. Battilotti, A. Borraccino, C. Colapicchioni, M. Tomassetti, and G. Visco, "A new ISFET device repsonsive to anionic detergents," Sensors and Actuators B, vol. 19, no. 13, pp. 321-328, 1994.

[13] J. Sànchez, A. Beltran, J. Alonso, C. Jiménez, and M. D. Valle, "Development of a new ion-selective field-effect transistor 
sensor for anionic surfactants: application to potentiometric titrations," Analytica Chimica Acta, vol. 382, no. 1-2, pp. 157164, 1999.

[14] J. Sànchez and M. D. Valle, "Photocurable ISFET for anionic surfactants. Monitoring of photodegradation processes," Talanta, vol. 54, no. 5, pp. 893-902, 2001.

[15] W. H. Chan, A. W. M. Lee, and J. Z. Lu, "Optode for the specific determination of anionic surfactants," Analytica Chimica Acta, vol. 361, no. 1-2, pp. 55-61, 1998.

[16] J. Sánchez and M. del Valle, "Determination of anionic surfactants employing potentiometric sensors-a review," Critical Reviews in Analytical Chemistry, vol. 35, no. 1, pp. 15-29, 2005.

[17] M. M. Hassanien, K. S. Abou-El-Sherbini, and G. A. E. Mostafa, "A novel tetrachlorothallate (III)-PVC membrane sensor for the potentiometric determination of thallium (III)," Talanta, vol. 59, no. 2, pp. 383-392, 2003.

[18] R. W. Cattrall and H. Freiser, "Coated wire ion selective electrodes," Analytical Chemistry, vol. 43, no. 13, pp. 19051906, 1971.

[19] H. James, G. Carmack, and H. Freiser, "Coated wire ion selective electrodes," Analytical Chemistry, vol. 44, no. 4, pp. 856-857, 1972.

[20] T. Fujinaga, S. Okazaki, and H. Freiser, "Ion selective electrodes responsive to anionic detergents," Analytical Chemistry, vol. 46, no. 12, pp. 1842-1844, 1974.

[21] M. Najafia, L. Maleki, and A. A. Rafati, "Novel surfactant selective electrochemical sensors based on single walled carbon nanotubes," Journal of Molecular Liquids, vol. 159, pp. 226229, 2011.

[22] M. J. Seguí, J. L. Sabater, R. M. Máñez, T. Pardo, F. Sancenón, and J. Soto, "Ion-selective electrodes for anionic surfactants using a new aza-oxa-cycloalkane as active ionophore," Analytica Chimica Acta, vol. 525, no. 1, pp. 83-90, 2004.

[23] D. O. Hummel, Handbook of Surfactant Analysis, Wiley, New York, NY, USA, 1999.

[24] G. A. E. Mostafa, "s-Benzylthiuronium PVC matrix membrane sensor for potentiometric determination of cationic surfactants in some pharmaceutical formulation," Journal of Pharmaceutical and Biomedical Analysis, vol. 41, no. 4, pp. 1110-1115, 2006.

[25] R. P. Buck and E. Lindner, "Recommendation for nomenclature of ion-selective electrodes," Pure and Applied Chemistry, vol. 66, no. 12, pp. 2527-2536, 1994.

[26] C. Maccà, "Response time of ion-selective electrodes: current usage versus IUPAC recommendations," Analytica Chimica Acta, vol. 512, no. 2, pp. 183-190, 2004.

[27] IUPAC, "Recommendations for nomenclature of ion-selective electrodes," Pure and Applied Chemistry, vol. 48, no. 1, pp. 127-132, 1976.

[28] APHA-AWWA-SPCF, "Standard methods for examination of water and waste-water," in Proceedings of the 16th American Public Health Association, p. 512A, Washington, DC, USA, 1985. 


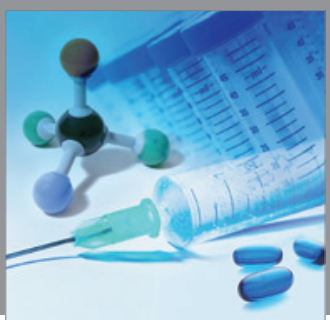

International Journal of

Medicinal Chemistry

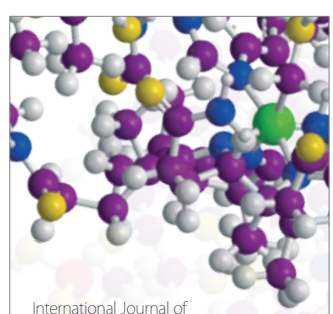

Carbohydrate Chemistry

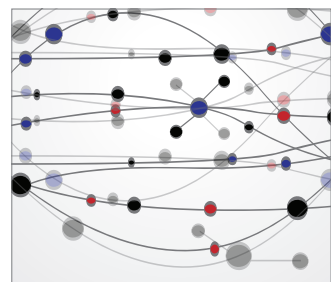

The Scientific World Journal
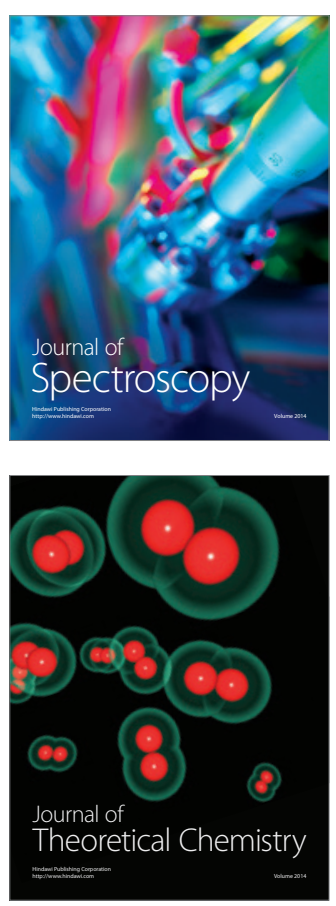
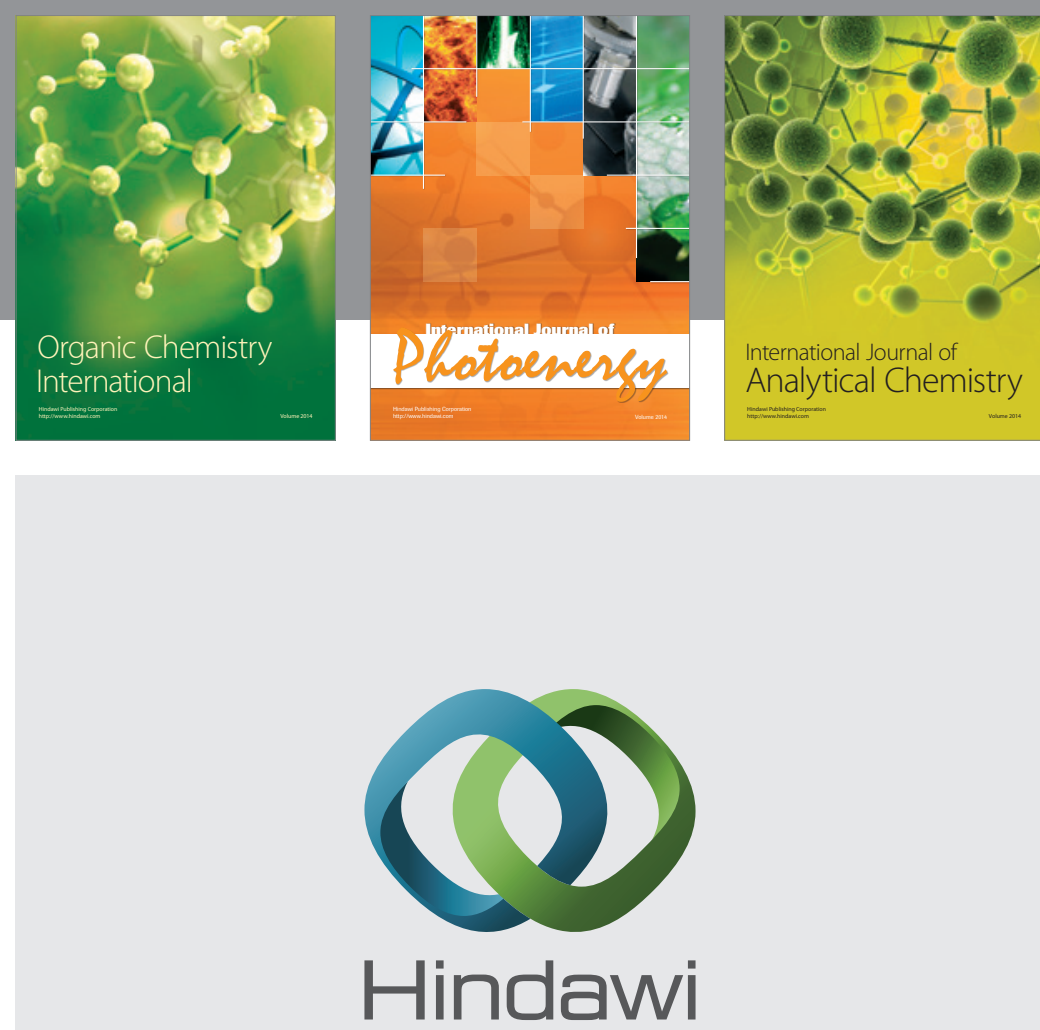

Submit your manuscripts at

http://www.hindawi.com
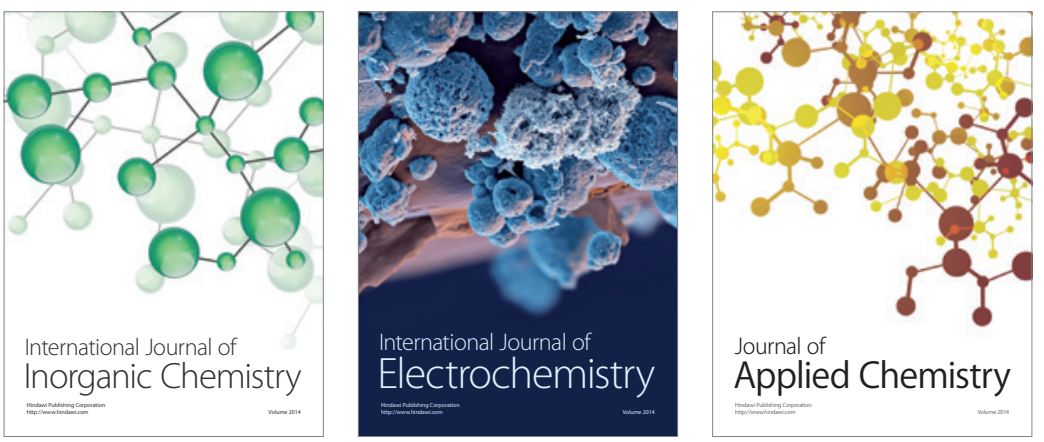

Journal of

Applied Chemistry
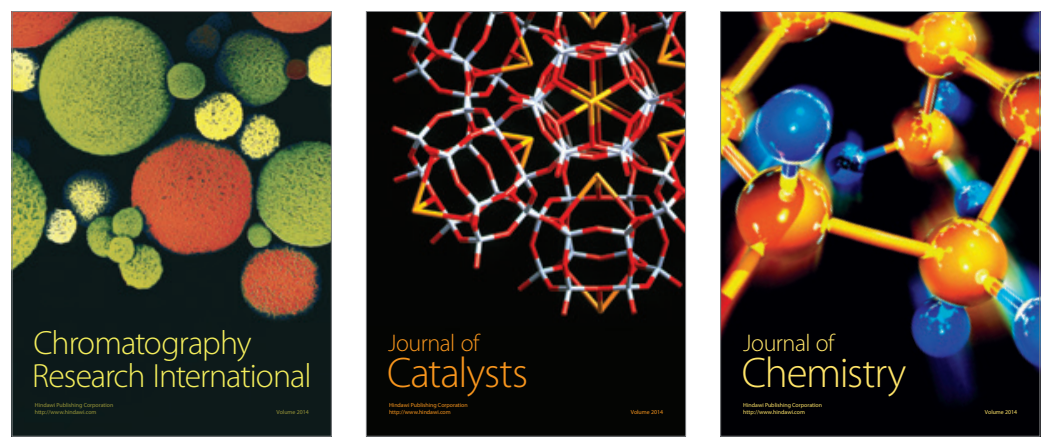
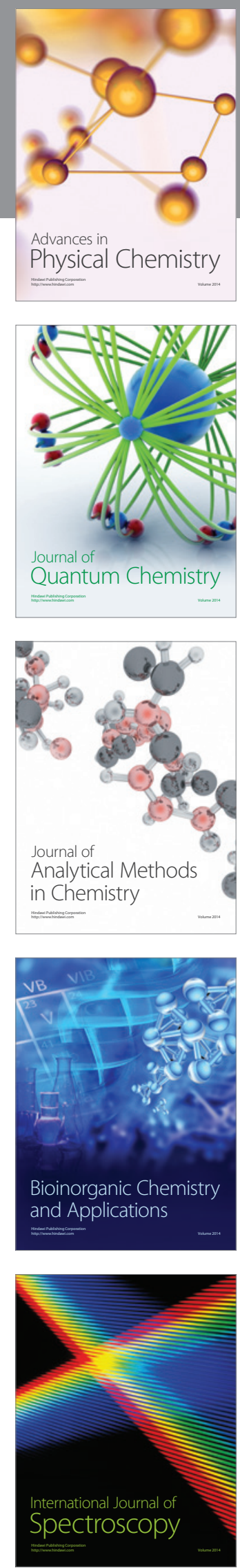